\title{
Erratum to: Immuno-PCR-based quantification of multiple phosphorylated tau-epitopes linked to Alzheimer's disease
}

\author{
David Singer • Hilkka Soininen • Irina Alafuzoff • \\ Ralf Hoffmann
}

Published online: 10 November 2009

(C) Springer-Verlag 2009

\section{Erratum to: Anal Bioanal Chem \\ DOI 10.1007/s00216-009-3208-8}

Regrettably, owing to a technical mishap, the following corrections were not carried out in the original manuscript prior to online publication. We offer our apologies to the readers.

The new addresses for Irina Alafuzoff are Kuopio University and Department of Genetics and Pathology, Uppsala University, 75185, Uppsala, Sweden.

Keywords: 'Digoxigenin' should be 'Cerebrospinal fluid'.

Page 1

Line 35: 'senile plaques' should read 'neuritic plaques'.

Line 36: 'SP' should read 'NP'.

The online version of the original article can be found at http://dx.doi. org/10.1007/s00216-009-3208-8.

\section{Singer $\cdot$ R. Hoffmann $(\bowtie)$}

Institute of Bioanalytical Chemistry, Center for Biotechnology

and Biomedicine, Faculty of Chemistry and Mineralogy,

Leipzig University,

Deutscher Platz 5,

04103 Leipzig, Germany

e-mail: hoffmann@chemie.uni-leipzig.de

\section{H. Soininen}

Department of Neurology, Kuopio University,

Yliopistonranta 1E,

70211 Kuopio, Finland

\section{Alafuzoff}

Section of Neuropathology, Kuopio University,

Yliopistonranta 1E,

70211 Kuopio, Finland

\section{Alafuzoff}

Department of Genetics and Pathology, Uppsala University,

75185 Uppsala, Sweden
Line 51 should read 'diagnosis before clinical symptoms manifest themselves'.

Page 3

Legend to Fig. 3

Line 7: 'pSer214+pThr231/pSer236' should read 'pSer214+pThr231/pSer235'.

Line 11: 'HPT-1/HPT10 ${ }_{\text {Dig }}$ ' should read 'HPT-101/HPT$1_{\text {Dig' }}$.

Line 118: 'from 1.56 to $0 \mathrm{pg} / \mu \mathrm{l}$ ' should read 'from 1,588 to $0 \mathrm{pg} / \mu \mathrm{l}$ '.

Page 4

Line 141 should read 'detection system (Fig.1). Thus, mAb HPT-1 and...'.

Line 163 should read 'studied mAb combinations (Fig. 2). For the mAb combination HPT-101 and HPT$1_{\text {Dig }}$, the detection limit of the quadruply...'.

Line 171 should read ' 101 by HPT-103 and the reverse sandwich format...'.

Line 172 should read: '.. HPT-1 as the capture $\mathrm{mAb}$ and HPT-101 $1_{\text {Dig }}$ as the detector...'.

Line 187 should read '... ranged from 600 to $1 \ldots, 200 \mathrm{pg} /$ $\mathrm{ml}$ in CSF...'.

Line 206 should read 'epitopes are useful biomarkers.'

Reference 1 should read 'Burns A, Iliffe S (2009) BMJ 338:b75'. 